\title{
Uncertainty analyses on the calculation of water environmental capacity by an innovative holistic method and its application to the Dongjiang River
}

\author{
Qiuwen Chen ${ }^{1,2, *}$, Qibin Wang ${ }^{2}$, Zhijie $\mathrm{Li}^{2}$, Ruonan $\mathrm{Li}^{2}$ \\ 1. Center for Eco-Environmental Research, Nanjing Hydraulic Research Institute, Nanjing 210029, China. E-mail: qchen@rcees.ac.cn \\ 2. State Key Laboratory of Environmental Aquatic Chemistry, Research Center for Eco-Environmental Sciences, Chinese Academy of sciences, \\ Beijing 100085, China
}

\section{A R T I C L E I N F O}

Article history:

Received 28 October 2013

Revised 4 April 2014

Accepted 8 April 2014

Available online 9 July 2014

Keywords:

Water environmental capacity

Model uncertainty

Holistic approach

Dongjiang River

\begin{abstract}
A B S T R A C T
The estimation and allocation of water environmental capacity (WEC) are essential to water quality management and social-economic interests. However, there is inevitable uncertainty in the capacity estimation due to model conceptualization, data collection and parameter calibration. An innovative holistic approach was developed, which took both independence and relevance between parameters into account to analyze the uncertainties in WEC calculation and estimate the margin of safety. The Dongiang River was taken as the case to demonstrate the method, focusing on the chemical oxygen demand and $\mathrm{NH}_{4}^{+}-\mathrm{N}$ that were the two major water quality problems in the river. The results showed that the proposed holistic approach is very promising and applicable compared to traditional methods of uncertainty analysis.
\end{abstract}

(c) 2014 The Research Center for Eco-Environmental Sciences, Chinese Academy of Sciences.

Published by Elsevier B.V.

\section{Introduction}

Management of water environmental capacity (WEC) (Wang et al., 1995; Han et al., 2010; Li et al., 2010) is a key factor in pollution control of water bodies (Arrow et al., 1995; Keller and Cavallaro, 2008). Based on the estimation of WEC, the total allowable amount of pollutants discharged into water bodies can be obtained and allocated properly among different industries and areas (Burn and Lence, 1992), in order to make sure that the emission quantities are within the water environmental carrying capacity.

However, there exist uncertainties in the process of calculating WEC, originating from water quality model conceptualization, parameter calibration and input data (Radwan et al., 2004; Lindenschmidt et al., 2007). Analysis and estimation of the safety interval of WEC in different hydrological periods can ensure the precision and reliability of the load allotment (Liu et al., 2012). If the safety interval is too small, it will increase the risk of exceeding water quality standards (Rezaie et al., 2007); while simply enlarging the safety interval could affect the use of the WEC and hence social- economic activities. Therefore, a proper safety interval must be provided for WEC management (Rezaie et al., 2009), which involves identifying major uncertainty sources, quantifying their degree and relative importance, and determining the safety interval of WEC (Tutmez, 2009; Warmink et al., 2010). Among different sources of model uncertainties, parameter uncertainty (Van Griensven et al., 2006; Shen et al., 2010; Li et al., 2010) is predominant and also widely present due to the increase of model complexity, which greatly increases the number of parameters involved.

Many approaches have been applied to analyze the parameter uncertainty, such as Bayesian updating (Borsuk and Stow, 2000; Borsuk et al., 2004), Monte Carlo simulation (Rezaie et al., 2007; Mannina and Viviani, 2010), probabilistic approach (Borsuk et al., 2002) and the methods based on them. Van Griensven et al. (2006) developed an automatic parameter calibration and uncertainty assessment method using response surfaces for evaluating the impacts of parameter uncertainty. Blasone et al. (2008a, 2008b) proposed the Markov Chain Monte Carlo (MCMC) method, which generates parameter values from a carefully constructed Markov

\footnotetext{
* Corresponding author. E-mail: qchen@rcees.ac.cn (Qiuwen Chen).
} 
chain; Stein (1987) and Owen (1992) introduced the Latin hypercube stratified sampling technique to the Monte Carlo method for global sensitivity and uncertainty analysis of parameters and input data in a soil organic carbon dynamics model at plot scale and river basin scale. Wang (2002) developed a method that embedded use of a neural network (NN) in a genetic algorithm to analyze the multiple-pattern parameters for robust water quality modeling. However, most of these methods are based on the statistical characteristic of a parameter, which is usually unknown a priori. Besides, they assume independence between multiple parameters, which is often not the case in reality.

This study developed an innovative holistic approach that took both independence and relevance between the parameters into account to analyze the uncertainties in WEC calculation and estimate the margin of safety. The mainstream of the Dongjiang River and its major tributaries were taken as the study case.

\section{Materials and methods}

The study built up a one-dimensional water quality model for chemical oxygen demand (COD) and $\mathrm{NH}_{4}^{+}-\mathrm{N}$, and used the monitoring data to calibrate the model. The validated model was used to estimate the daily WEC of COD and $\mathrm{NH}_{4}^{+}-\mathrm{N}$ under typical dry flow conditions. Finally the safety intervals of WEC were determined by an innovative holistic method.

\subsection{Study area}

The Dongjiang River basin $\left(113^{\circ} 52^{\prime} \mathrm{E}-115^{\circ} 52^{\prime} \mathrm{E}, 22^{\circ} 38^{\prime} \mathrm{N}-25^{\circ} 14^{\prime} \mathrm{N}\right)$ is located in the northeast of the Pearl River Delta. The total area of the basin is $35,340 \mathrm{~km}^{2}, 90.1 \%$ of which resides in Guangdong Province. It covers six cities, including Heyuan, Huizhou, Dongguan, Shenzhen, Shaoguan and Meizhou. The rainfall in the basin is very rich, with an annual average of $1950 \mathrm{~mm}$. The rainfall decreases from downstream to upstream (Fig. 1).

The Dongjiang River originates in Xunwu of Jiangxi Province. The main stream flows through Heyuan, Huizhou, and Shilong and discharges into the South China Sea. The river is $562 \mathrm{~km}$ long, and $77.4 \%$ of it is in Guangdong Province. The river supplies almost $90 \%$ of the total water consumption of Hong Kong, which makes it highly important. The water quality in the river is at present fairly good; however, there is an increasing trend of $\mathrm{COD}$ and $\mathrm{NH}_{4}^{+}-\mathrm{N}$ concentrations. The study focuses on these parameters in the mainstream and the major tributaries (Fig. 1).

\subsection{Hydro-environmental model}

A one-dimensional water quality model is developed which contains a flow module and an advection-diffusion-reaction

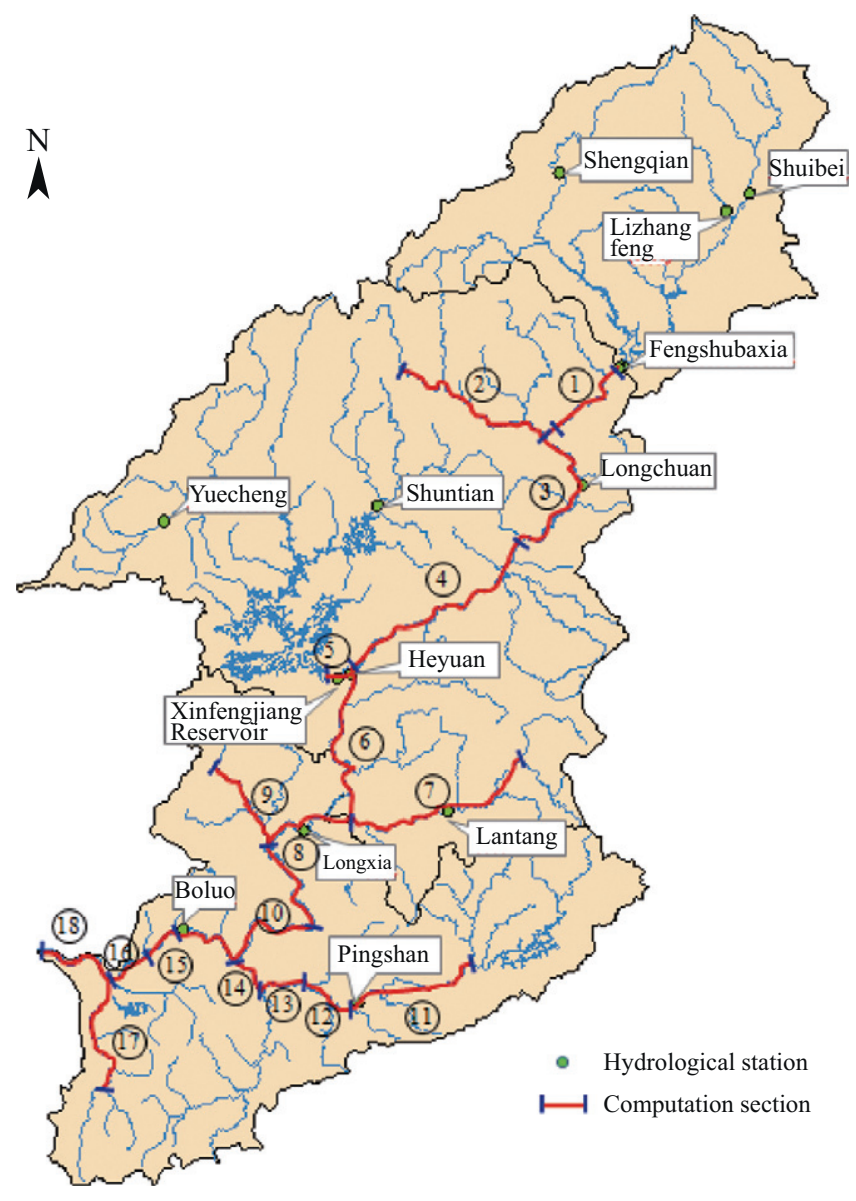

Fig. 1 - Control unit of water environment capacity for main stream and tributaries of the Dongjiang River. The 1-18 means the calculation segments. 
module. The flow module is based on the Saint-Venant equations (Stępień, 1984; Saleh et al., 2013):

$\frac{\partial A}{\partial t}+\frac{\partial Q}{\partial x}=0$

$\frac{\partial Q}{\partial t}+\frac{\partial}{\partial x}\left(\frac{Q^{2}}{A}\right)+g A \frac{\partial H}{\partial x}+\frac{g Q}{C^{2}} \frac{|Q|}{R A}=0$

where, $A\left(\mathrm{~m}^{2}\right)$ is the flow area; $\mathrm{Q}\left(\mathrm{m}^{3} / \mathrm{sec}\right)$ is the discharge; $t(\mathrm{sec})$ is the time; $x(\mathrm{~m})$ is the distance along the channel length; $g\left(\mathrm{~m} / \mathrm{sec}^{2}\right)$ is the acceleration due to gravity; $H(\mathrm{~m})$ is the water level; $C\left(\mathrm{~m}^{1 / 2} / \mathrm{sec}\right)$ is the Chezy coefficient; and $R(\mathrm{~m})$ is the hydraulic radius.

The one-dimensional advection-diffusion-reaction module for substance is described by Eq. (3).

$\frac{\partial A C}{\partial t}+\frac{\partial Q C}{\partial x}=\frac{\partial}{\partial x}\left(D_{x} \frac{\partial A C}{\partial x}\right)+A S+A f_{\mathrm{R}}(C, t)$

where, $C(\mathrm{mg} / \mathrm{L})$ is the concentration of pollutants; $D_{x}\left(\mathrm{~m}^{2} / \mathrm{sec}\right)$ is the dispersion coefficient in the $x$ direction; $S(\mathrm{mg} /(\mathrm{L} \cdot \mathrm{sec}))$ is the source or sink terms; and $f_{\mathrm{R}}$ is the reaction terms. The reaction term for COD is given by:

$\frac{\partial C_{\mathrm{COD}}}{\partial t}=-k_{\mathrm{COD}} C_{\mathrm{COD}}$

where, $C_{\mathrm{COD}}(\mathrm{mg} / \mathrm{L})$ is the concentration of COD; and $k_{\mathrm{COD}}\left(\right.$ day $\left.^{-1}\right)$ is the degradation coefficient.

The transformation of nitrogen in water involves a series of complicated biochemical reactions, including ammonification, nitrification and denitrification processes (Nolan et al., 2002; Ryzhakov et al., 2010). In the Dongjiang River, the dissolved oxygen (DO) concentration is mostly higher than $4 \mathrm{mg} / \mathrm{L}$, which is not suitable for the denitrification reaction. The $\mathrm{pH}$ is about 7, which means that the acidity is weak, and could hardly generate an inhibitory effect to nitrification. With low organic nitrogen concentration and high DO concentration, ammonification is negligible. Nitrate is the predominant species of nitrogen in the river, and thus among the nitrogen conversion processes only nitrification is considered. The release of $\mathrm{NH}_{4}^{+}-\mathrm{N}$ from sediment into the water is negligible as well due to the low organic nitrogen and the coarse sandy riverbed (Liao et al., 2013).

In the $\mathrm{NH}_{4}^{+}-\mathrm{N}$ model, the release of $\mathrm{NH}_{4}^{+}-\mathrm{N}$ from sediment into the overlying water is ignored, and only the amount in the water body is taken into account. Since the DO concentration is high in the Dongjiang River, the intermediate product nitrite is unstable. Therefore, the reaction term $f_{\mathrm{R}}$ for $\mathrm{NH}_{4}^{+}-\mathrm{N}$ is given by Eq. (5).

$\frac{\partial \mathrm{C}_{\mathrm{NH}_{4}{ }^{+}-\mathrm{N}}}{\partial t}=-k_{\mathrm{NH}_{4}{ }^{+}-\mathrm{N}} \mathrm{C}_{\mathrm{NH}_{4}{ }^{+}-\mathrm{N}}$

where, $\mathrm{C}_{\mathrm{NH}_{4}{ }^{+}-\mathrm{N}}(\mathrm{mg} / \mathrm{L})$ is the concentration of $\mathrm{NH}_{4}^{+}-\mathrm{N} ; k_{\mathrm{NH}_{4}{ }^{+}-\mathrm{N}}$ $\left(\right.$ day $\left.^{-1}\right)$ is the nitrification rate. In the one-dimensional $\mathrm{NH}_{4}^{+}-\mathrm{N}$ model, $k_{\mathrm{NH}_{4}{ }^{+}-\mathrm{N}}$ is highly sensitive to temperature.

$k_{\mathrm{NH}_{4}{ }^{+}-\mathrm{N}}=\theta_{2}{ }^{\mathrm{T}-20} k_{\mathrm{NH}_{4}{ }^{+}-\mathrm{N}}^{20^{\circ} \mathrm{C}}$

where, $\theta_{2}$ is the temperature coefficient for nitrification; $\mathrm{T}\left({ }^{\circ} \mathrm{C}\right)$ is the water temperature; and $\left.k_{\mathrm{NH}_{4}{ }^{+}-\mathrm{N}}^{20^{\circ} \mathrm{day}}{ }^{-1}\right)$ is the nitrification rate at $20^{\circ} \mathrm{C}$.

\subsection{Water environmental capacity estimation}

According to the designed function of the water body, the study area was divided into 18 segments (Fig. 1), and the corresponding water quality target was specified (Table 2).

The developed water quality model was applied to calculate the WEC according to the head-control principle, which ensures that the water quality at the upstream boundary of the section meets the target of the section. Under this principle, the calculation is started from the last section of the river. The dilution capacity is computed by Eq. (7):

$m_{0}=Q_{0}\left(C_{s}-C_{0}\right)$

And then the WEC at ith section is given by Eq. (8):

$m_{i}=\left(Q_{i}+q_{i}\right) C_{s}-Q_{i} C_{i}$.

The WEC of the whole segment is

$m=86.4\left\{Q_{0}\left(C_{s}-C_{0}\right)+\sum_{i=1}^{n}\left(\left(Q_{i}+q_{i}\right) C_{s}-Q_{i} C_{i}\right)\right\}$

where, $m_{0}(\mathrm{~kg} /$ day $)$ is the dilution capacity; $m_{\mathrm{i}}(\mathrm{kg} /$ day) is the WEC for the $i^{\text {th }}$ section; $m$ (kg/day) is the WEC for the whole segment; $Q_{0}\left(\mathrm{~m}^{3} / \mathrm{sec}\right)$ is the inflow discharge at the very beginning of the segment; $C_{\mathrm{s}}(\mathrm{mg} / \mathrm{L})$ is the objective concentration of the water quality at the end of the segment according to the water quality target; $C_{0}(\mathrm{mg} / \mathrm{L})$ is the objective concentration of the water quality at the beginning of segment; $Q_{i}\left(\mathrm{~m}^{3} / \mathrm{sec}\right)$ is the inflow discharge at ith section-beginning; $C_{i}$ is the concentration of the $i^{\text {th }}$ section; $k\left(\right.$ day $\left.^{-1}\right)$ is the comprehensive degradation coefficient; and $q_{i}\left(\mathrm{~m}^{3} / \mathrm{sec}\right)$ is the flow rate at the $i^{\text {th }}$ section. $Q_{i}$ and $C_{i}$ are computed through the calibrated water quality model. The schematic diagram of the section-head control method is shown in Fig. 2.

\subsection{Safety interval of water environmental capacity}

After local sensitivity analyses (Chen et al., 2012), the most sensitive parameters for flow and water quality modules were identified respectively. Then the study proposed a holistic approach, which took both independence and relevance between the factors into account, to estimate the uncertainties in WEC calculation incurred by these parameters. For a section,

$$
\begin{aligned}
& Q=f_{1}\left(q_{\mathrm{b}}, l_{\text {flow }, 1}, \cdots l_{\text {flow }, i}, \cdots l_{\text {flow }, n}, l_{\text {flow }}\right) \\
& C=f_{2}\left(q_{\mathrm{b}}, c_{\mathrm{b}}, l_{\text {flow }, 1}, \cdots l_{\text {flow }, i}, \cdots l_{\text {flow }, n}, l_{\mathrm{wq}, 1}, \cdots l_{\mathrm{wq}, i}, \cdots l_{\mathrm{wq}, n} \cdots, l_{\mathrm{wq}}\right) \\
& m=Q\left(C_{\mathrm{S}}-C\right)
\end{aligned}
$$

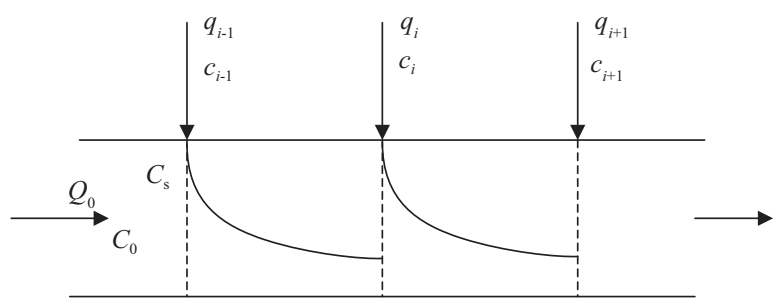

Fig. 2 - Schematic diagram of section-beginning control method. 

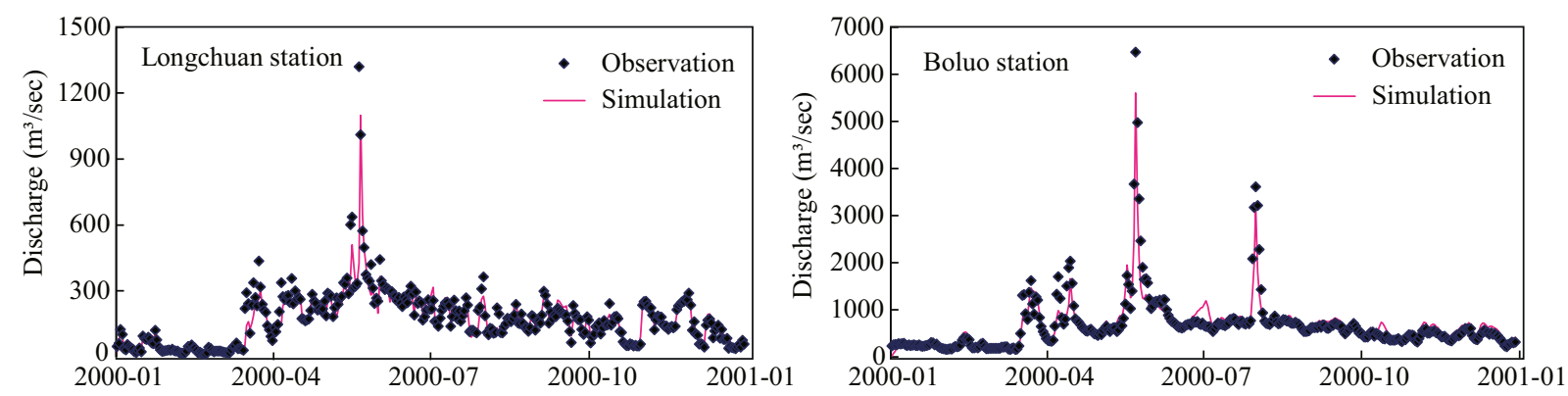

Fig. 3 - Validation of discharges of the flow module at Longchuan and Boluo stations.

$\frac{\partial m}{\partial q_{\mathrm{b}}}=\frac{\partial Q}{\partial q_{\mathrm{b}}}\left(C_{\mathrm{S}}-C\right)-\frac{\partial C}{\partial q_{\mathrm{b}}} Q$

$\frac{\partial m}{\partial c_{\mathrm{b}}}=-\frac{\partial C}{\partial c_{\mathrm{b}}} Q$

$\frac{\partial m}{\partial l_{\text {flow }}}=\frac{\partial Q}{\partial l_{\text {flow }}}\left(C_{S}-C\right)-\frac{\partial C}{\partial l_{\text {flow }}} Q$

$\frac{\partial m}{\partial l_{\mathrm{wq}}}=\frac{\partial Q}{\partial l_{\mathrm{wq}}}\left(C_{\mathrm{S}}-C\right)-\frac{\partial C}{\partial l_{\mathrm{wq}}} Q$

where, $Q\left(\mathrm{~m}^{3} / \mathrm{sec}\right)$ is the discharge at the end of the section; $C_{\mathrm{s}}$ $(\mathrm{mg} / \mathrm{L})$ is the environmental standard for a specific pollutant concentration; $C(\mathrm{mg} / \mathrm{L})$ is the calculated concentration from the water quality model; $q_{b}\left(\mathrm{~m}^{3} / \mathrm{sec}\right)$ is the discharge at the boundary; $c_{b}(\mathrm{mg} / \mathrm{L})$ is the concentration at the boundary; $l_{f l o w}, i$ is the $i^{\text {th }}$ hydrological parameter in the flow module, and $l_{\text {flow }}$ is the most sensitive hydrological parameter identified by local sensitive analysis; $l_{\mathrm{wq}, i}$ is the $i^{\text {th }}$ water quality parameter in the water quality module, and $l_{\mathrm{wq}}$ is the most sensitive water quality parameter identified by local sensitive analysis.

Eqs. (13) to (16) are the differential forms of the change of the estimated WEC resulting from the change of boundaries and most sensitive parameters in the model. It is known that Eqs. (10) and (11) are non-linear, thus the relationship between WEC and boundary conditions as well as the parameters are non-linear. If a difference scheme is taken, Eq. (12) becomes Eq. (17):

$\Delta m_{\mathrm{q}}=\delta_{m_{\mathrm{q}}}\left[\frac{Q_{q_{\mathrm{b}}+\Delta_{q_{\mathrm{b}}}}-Q_{q_{\mathrm{b}}}}{q_{\mathrm{b}}+\Delta q_{\mathrm{b}}-q_{\mathrm{b}}}\left(C_{\mathrm{s}}-C\right)-\frac{C_{q_{\mathrm{b}}+\Delta_{q_{\mathrm{b}}}}-C_{q_{\mathrm{b}}}}{q_{\mathrm{b}}+\Delta q_{\mathrm{b}}-q_{\mathrm{b}}} Q\right] \Delta q_{\mathrm{b}}$

\begin{tabular}{|c|c|c|c|}
\hline Parameter & Symbol & Value & $\begin{array}{c}\text { Value from } \\
\text { literature } \\
\text { (Tan et al., 2007) }\end{array}$ \\
\hline $\begin{array}{l}\text { Decay rate of COD at } \\
20^{\circ} \mathrm{C}\left(\text { day }^{-1}\right)\end{array}$ & $k_{\mathrm{COD}}^{20^{\circ} \mathrm{C}}$ & 0.07 & $0.1-0.2$ \\
\hline $\begin{array}{l}\text { Temperature dependent } \\
\text { coefficient for COD decay }\end{array}$ & $\theta_{1}$ & 1.074 & 1.0-1.1 \\
\hline $\begin{array}{l}\text { Nitrification rate at } \\
20^{\circ} \mathrm{C}\left(\text { day }^{-1}\right)\end{array}$ & $k_{\mathrm{NH}_{4}{ }^{+}-\mathrm{N}}^{20^{\circ} \mathrm{C}}$ & 0.1 & $0.05-0.15$ \\
\hline $\begin{array}{l}\text { Temperature dependent } \\
\text { coefficient for nitrification }\end{array}$ & $\theta_{2}$ & 1.045 & $1.0-1.1$ \\
\hline
\end{tabular}

$\delta_{m_{\mathrm{q}}}=\delta(\Delta q / q)$.

When $\Delta q \rightarrow 0, \delta m_{\mathrm{q}}$ is equal to 1 , so that Eq. (18) can be changed into the following Eq. (19):

$\lim _{\Delta q / q \rightarrow 0} \delta_{m_{q}}=1$

$\Delta m_{\mathrm{c}}=\delta_{m_{\mathrm{c}}}\left[\frac{Q_{c_{\mathrm{b}}+\Delta_{c_{\mathrm{b}}}}-Q_{c_{\mathrm{b}}}}{c_{b}+\Delta c_{\mathrm{b}}-c_{b}}\left(C_{\mathrm{S}}-C\right)-\frac{C_{c_{\mathrm{b}}}+\Delta_{c_{\mathrm{b}}}-C_{c_{\mathrm{b}}}}{c_{b}+\Delta c_{b}-c_{b}} Q\right] \Delta c_{\mathrm{b}}$.

Since $\frac{\partial Q}{\partial c_{\mathrm{b}}}=0$, Eq. (20) can be changed into Eq. (21):

$\Delta m_{\mathrm{c}}=-\delta_{m_{\mathrm{c}}} \frac{C_{c_{\mathrm{b}}+\Delta_{c_{\mathrm{b}}}}-C_{c_{\mathrm{b}}}}{c_{\mathrm{b}}+\Delta c_{\mathrm{b}}-c_{\mathrm{b}}} Q \Delta c_{\mathrm{b}}$

Similarly,

$\Delta m_{l_{\text {flow }}}=\delta_{l_{\text {flow }}} k_{l_{\text {flow }}}\left[\frac{Q_{l_{\text {flow }}+\Delta l_{\text {flow }}}-Q_{l_{\text {flow }}}}{l_{\text {flow }}+\Delta l_{\text {flow }}-l_{\text {flow }}}\left(C_{S}-C\right)-\frac{C_{l_{\text {flow }}+\Delta l_{\text {flow }}}-C_{l_{\text {flow }}}}{l_{\text {flow }}+\Delta l_{\text {flow }}-l_{\text {flow }}} Q\right] \Delta l_{\text {flow }}$

$\Delta m_{l_{\mathrm{wq}}}=-\delta_{l_{\mathrm{wq}}} k_{l_{\mathrm{wq}}} \frac{C_{l_{\mathrm{wq}}+\Delta l_{\mathrm{wq}}}-C_{l_{\mathrm{wq}}}}{l_{\mathrm{wq}}+\Delta l_{\mathrm{wq}}-l_{\mathrm{wq}}} Q \Delta l_{\mathrm{wq}}$

$U=\left[\frac{1}{2} \sum_{k \neq j} \sum_{j}<\Delta m_{k}, \Delta m_{j}>\right]^{1 / 2}, j \in A, k \in A, A=\left\{q, c, l_{\text {flow }}, l_{\text {wq }}\right\}$.

Because different factors are independent, the correlation coefficient $\rho_{j, k}$ of uncertainty intervals is set as zero.

$<\Delta m_{j}, \Delta m_{k}>=\Delta m_{j}{ }^{2}+\Delta m_{k}{ }^{2}+2 \rho_{j, k} \Delta m_{j} \Delta m_{k}=\Delta m_{j}{ }^{2}+\Delta m_{k}{ }^{2}$

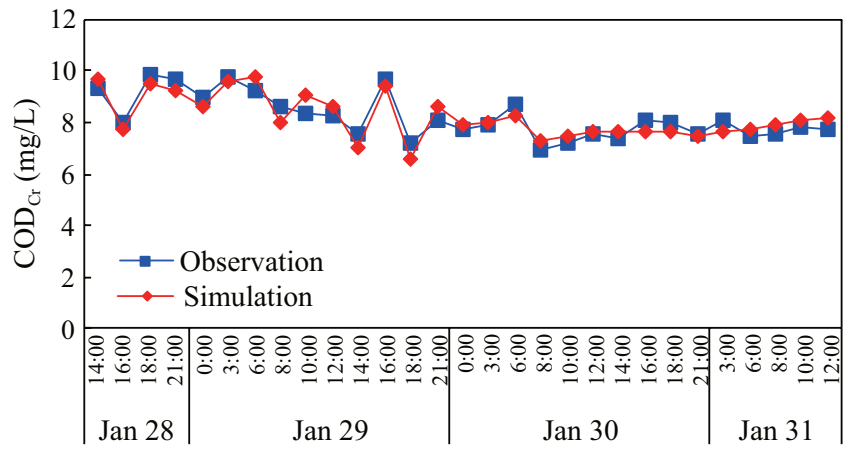

Fig. 4 - Validation of CODcr of water quality module at the Lingxia Station. 
$U=\left(\sum_{j} m_{j}{ }^{2}\right)^{1 / 2}$

where, $\Delta m_{\mathrm{q}}$ (kg/day) is the difference value of WEC; $\Delta q_{\mathrm{b}}\left(\mathrm{m}^{3} / \mathrm{sec}\right)$ is the incremental discharge at the boundary; $\Delta q\left(\mathrm{~m}^{3} / \mathrm{sec}\right)$ is the incremental discharge at the section selected; $\Delta c_{b}(\mathrm{mg} / \mathrm{L})$ is the incremental concentration at the boundary; $\Delta l_{\text {flow }}$ is the incremental change of the most sensitive hydrological parameter identified by local sensitive analysis; $\Delta l_{\mathrm{wq}}$ is the incremental change of the most sensitive water quality parameter identified by local sensitive analysis; $\delta_{\mathrm{mq}}, \delta_{\mathrm{mc}}, \delta_{\text {lflow }}$ and $\delta_{\text {lwq }}$ are amplification factors caused by $\Delta q_{\mathrm{b}}, \Delta c_{\mathrm{b}}, \Delta \mathrm{l}_{\text {flow }}$ and $\Delta \mathrm{l}_{\mathrm{wq}}$, respectively; $\delta$ is the function of $\Delta q / q ; k_{l_{\text {flow }}}\left(\right.$ day $\left.^{-1}\right)$ and $k_{l_{\text {wq }}}\left(\right.$ day $\left.^{-1}\right)$ are the degradation coefficients; $q\left(\mathrm{~m}^{3} / \mathrm{sec}\right)$ is the discharge; and $U$ is the uncertainty of WEC.

Through the analysis, the uncertainties of WEC induced by the most sensitive parameter and the boundary conditions of the model can be quantified.

\section{Results and discussion}

The daily observed discharges in 1998 at Boluo station were used to validate the flow module, and the result is shown in Fig. 3.

From Fig. 3 it can be seen that the simulated discharges fit well with the observations, and the $R^{2}$ between observations and simulations are 0.88 and 0.92 for Longchuan and Boluo stations, respectively. This implies that the flow module developed in this study is reliable to simulate the flow process in the river, and can be applied to the subsequent water quality calculation.

To calibrate and validate the water quality modules, a monitoring campaign was conducted in the mainstream and major tributaries during 12 a.m. on Jan. 28 to 12 a.m. on Jan. 31 in 2010. Samples were taken simultaneously at 4 stations every $2 \mathrm{hr}$, and the monitored data included discharge, water level,

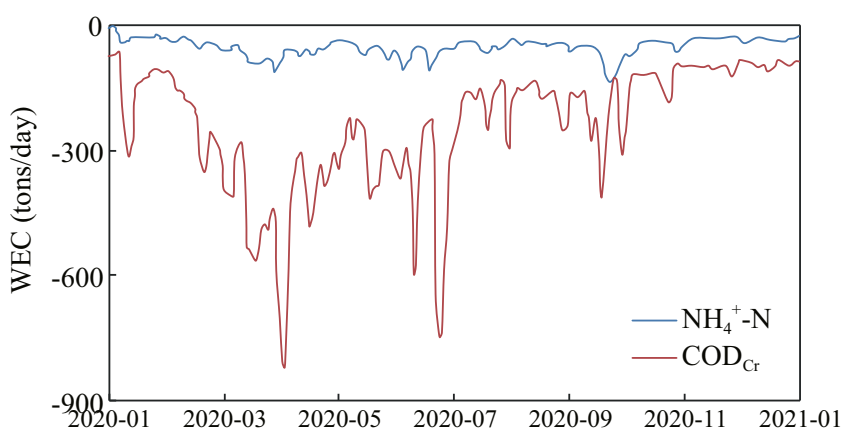

Fig. 5 - Water environmental capacity of COD and $\mathrm{NH}_{4}^{+}-\mathrm{N}$ in computation section $\mathbf{1 0}$ in $\mathbf{2 0 2 0}$ for typical dry flow conditions.

temperature, $\mathrm{pH}$, and concentrations of $\mathrm{COD}, \mathrm{DO}, \mathrm{NH}_{4}^{+}-\mathrm{N}, \mathrm{NO}_{3}^{-}-\mathrm{N}$, $\mathrm{PO}_{4}^{3+}-\mathrm{P}$, total nitrogen, and total phosphorus. The calibration of COD is given in Fig. 3. After calibration by a genetic algorithm (Chen et al., 2014), the values of the main parameters are listed in Table 1. For comparison, the reference values from literature (Tan et al., 2007) are provided in Table 1 as well.

It is also seen from Fig. 4 that the calibration of the water quality module is acceptable, as the $R^{2}$ value between observations and simulations is as high as 0.83 for COD. Although four days' data is usually considered short for calibration and validation of a water quality model, these are high quality data that were simultaneously taken at 4 stations every $2 \mathrm{hr}$. In addition, the seasonality of precipitation and temperature is not obvious in the studied river. Therefore, the data could provide reliable calibration for the model, and the calibrated model is valid for application.

Taking the daily flow of a typical dry year as the designed hydrologic condition, and 2010 as the base-year, the WEC in 2020 for typical dry flow conditions was estimated, and the results are shown in Table 2, in which minus means reduction.

\section{Table 2 - Water environmental capacities and the uncertainty intervals of each segment for typical dry year.}

\begin{tabular}{|c|c|c|c|c|c|c|c|c|}
\hline \multirow[t]{4}{*}{ Segment no. } & \multicolumn{2}{|c|}{ Water quality target } & \multicolumn{6}{|c|}{ Water environmental capacity and the uncertainty interval (ton/year) } \\
\hline & \multirow[t]{3}{*}{ Year 2010 class } & \multirow[t]{3}{*}{ Year 2020 class } & \multicolumn{6}{|c|}{ Year 2020} \\
\hline & & & \multicolumn{3}{|c|}{ COD } & \multicolumn{3}{|c|}{$\mathrm{NH}_{4}^{+}-\mathrm{N}$} \\
\hline & & & Lower bound & Mean & Upper bound & Lower bound & Mean & Upper bound \\
\hline 1 & II & II & 467 & 575 & 682 & 38 & 47 & 56 \\
\hline 2 & II & II & 1160 & 1434 & 1708 & 91 & 110 & 130 \\
\hline 3 & II & II & 1677 & 2092 & 2508 & 172 & 214 & 255 \\
\hline 4 & II & II & 5096 & 6371 & 7646 & 428 & 526 & 623 \\
\hline 5 & II & II & -911 & -762 & -612 & -253 & -214 & -175 \\
\hline 6 & II & II & 3844 & 4949 & 6054 & 299 & 379 & 459 \\
\hline 7 & II & II & 1769 & 2254 & 2739 & 130 & 161 & 192 \\
\hline 8 & II & II & 6409 & 7784 & 9158 & 512 & 613 & 713 \\
\hline 9 & II & II & 503 & 627 & 750 & 40 & 50 & 60 \\
\hline 10 & II & II & -4181 & -5400 & -6618 & -511 & -634 & -757 \\
\hline 11 & II & II & 1764 & 2170 & 2576 & 124 & 154 & 183 \\
\hline 12 & III & III & -2718 & -2270 & -1822 & -70 & -59 & -48 \\
\hline 13 & III & II & 618 & 768 & 919 & 48 & 59 & 71 \\
\hline 14 & IV & II & -29688 & -24960 & -20233 & -1937 & -1619 & -1300 \\
\hline 15 & II & II & 548 & 677 & 805 & 44 & 54 & 65 \\
\hline 16 & II & II & 1498 & 1889 & 2280 & 116 & 142 & 169 \\
\hline 17 & IV & III & -5376 & -4528 & -3679 & -1066 & -898 & -730 \\
\hline 18 & III & II & -16762 & -14020 & -11277 & -1784 & -1495 & -1207 \\
\hline
\end{tabular}



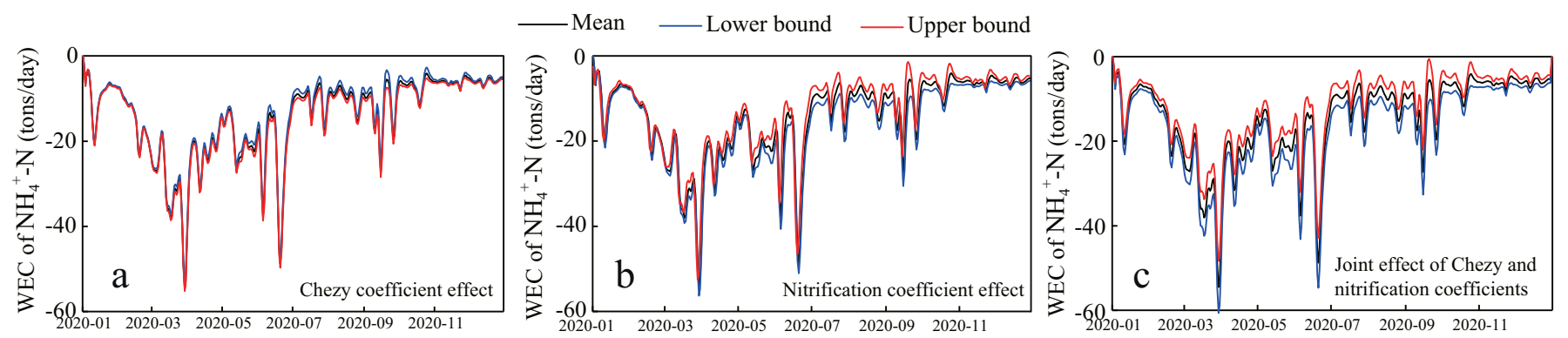

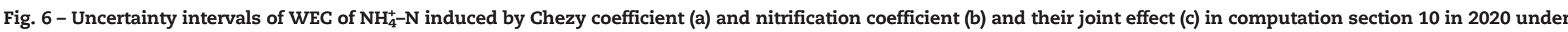
typical dry flow conditions. 
Taking the segment 10 as an example, the daily WEC of COD and $\mathrm{NH}_{4}^{+}-\mathrm{N}$ in the typical dry year is shown in Fig. 5.

The results in Table 2 show that the WEC in the lower reach of the Dongjiang River is negative, which means that pollution load reduction is necessary. The reduction amount is much higher in the segment where the Xizhi River flows into the Dongjiang River, which is because the water quality in the Xizhi River is very bad. In some segments, the target of water quality is set too high to be realized. For example, the water quality target of segment 14 in 2020 is designed to be class II, which could not be achieved even without any discharge in this section. It should be pointed out that the study uses the sectionbeginning control method to compute the WEC, and the result is relatively conservative, which means that the actual WEC should be slightly larger than the calculated value.

The uncertainties from multiple factors were analyzed synthetically under typical dry flow conditions in the Dongjiang River basin by the proposed method. Fig. 6 presents the uncertainty of WEC of $\mathrm{NH}_{4}^{+}-\mathrm{N}$ induced by the Chezy coefficient and nitrification coefficient and by both. Finally, the uncertainty intervals of the WEC of each segment were obtained, based on the method introduced above, and the results in 2020 for typical dry flow conditions are shown in Table 2.

Although the hydro-environmental model is accurate enough for calculating WEC in the mainstream and major tributaries of the Dongjiang River, there are still differences between observation and simulation due to uncertainties from model parameters and other aspects (Van Griensven et al., 2006; Shen et al., 2010). The uncertainty interval of WEC calculation is determined by computing the orthogonal sum of the uncertainties introduced by different parameters. From Fig. 6, it is seen that the uncertainty induced by hydraulic parameters such as the Chezy coefficient is very small in the WEC calculations. However, the uncertainty caused by water quality parameters such as the nitrification coefficient is significant in the WEC calculations. The joint effect of the Chezy coefficient and nitrification coefficient is not much different from that of the nitrification coefficient alone, which is because uncertainty from the hydraulics model is negligible.

Compared to the fuzzy $\alpha$-cut approach which was widely used in the previous studies (Rezaie et al., 2007; Blasone et al., 2008a), the proposed method in this research does not require the distribution function of the parameters, which is usually unknown a priori. Also unlike the Monte-Carlo approach, the proposed method does not need to generate a large number of random values and conduct hundreds of runs, so that it significantly reduces computation loads. Different from the generalized likelihood uncertainty estimation (Li et al., 2013) which required orthogonal relations between parameters, the proposed method can take both independence and relevance between parameters into account, greatly improving the simplicity.

\section{Conclusions}

WEC is calculated based on hydro-environmental models; consequently, there must be uncertainties in the results induced by parameters and boundary conditions. Therefore, great attention should be paid to analyze the uncertainties so as to secure the target water quality in the control sections. The study developed a holistic method for uncertainty analyses of WEC estimation, and its application to the Dongiang River proved that the proposed approach is very promising and applicable compared to traditional methods in uncertainty analyses of multiple parameters.

\section{Acknowledgments}

The authors are grateful to the funding from the National Basic Research Program (973) of China (No. 2010CB429004), the Chinese Academy of Sciences (No. KZZD-EW-10-02), and the National Natural Science Foundation of China (No. 51279196). The corresponding author is funded by Nanjing Hydraulic Research Institute (No. Y913017) and Ministry of Communication (No. 2011328222120).

\section{R E F E R E N C E S}

Arrow, K., Bolin, B., Costanza, R., Dasgupta, P., Folke, C., Holling, C. S., et al., 1995. Economic growth, carrying capacity, and the environment. Ecol. Econ. 15 (2), 91-95.

Blasone, R.S., Madsen, H., Rosbjerg, D., 2008a. Uncertainty assessment of integrated distributed hydrological models using GLUE with Markov chain Monte Carlo sampling. J. Hydrol. 353 (1), 18-32.

Blasone, R.S., Vrugt, J.A., Madsen, H., Rosbjerg, D., Robinson, B.A., Zyvoloskie, G.A., 2008b. Generalized likelihood uncertainty estimation (GLUE) using adaptive Markov Chain Monte Carlo sampling. Adv. Water Resour. 31 (4), 630-648.

Borsuk, M.E., Stow, C.A., 2000. Bayesian parameter estimation in mixed-order model of BOD decay. Water Resour. 34 (6), 1830-1836.

Borsuk, M.E., Stow, C.A., Reckhow, K.H., 2002. Predicting the frequency of water quality standard violations: a probabilistic approach for TMDL development. Environ. Sci. Technol. 36 (10), 2109-2115.

Borsuk, M.E., Stow, C.A., Reckhow, K.H., 2004. A Bayesian network of eutrophication models for synthesis, prediction, and uncertainty analysis. Ecol. Model. 173 (2-3), 219-239.

Burn, D.H., Lence, B.J., 1992. Comparison of optimization formulations for waste-load allocations. J. Environ. Eng. 118 (4), 597-612.

Chen, Q., Wu, W., Blanckaert, K., Ma, J., Huang, G., 2012. Optimization of water quality monitoring network in a large river by combining measurements, a numerical model and matter-element analyses. J. Environ. Manag. 110, 116-124.

Chen, Q., Zhang, C., Recknagel, F., Guo, J., Blanckaert, K., 2014. Adaptation and multiple parameter optimization of the simulation model SALMO as prerequisite for scenario analysis on a shallow eutrophic Lake. Ecol. Model. 273, 109-116.

Han, M., Mu, J., Sun, F., Cheng, L., Hao, Z., 2010. Estimation of water environment capacity: example as four basin in Shandong province, China. Procedia Environ. Sci. 2, 1919-1926.

Keller, A.A., Cavallaro, L., 2008. Assessing the US clean water Act 303(d) listing process for determining impairment of a water body. J. Environ. Manag. 86 (4), 699-711.

Li, Y.X., Qiu, R.Z., Yang, Z.F., Li, C.H., Yu, J.S., 2010. Parameter determination to calculate water environmental capacity in Zhangweinan Canal Sub-basin in China. J. Environ. Sci. 22 (6), 904-907.

Li, Z., Chen, Q., Xu, Q., Blanckaert, K., 2013. Generalized Likelihood Uncertainty Estimation (GLUE) method in uncertainty analysis 
of numerical eutrophication models: take BLOOM as an example. Math. Probl. Eng. http://dx.doi.org/10.1155/2013/ 701923 (Article ID 701923).

Liao, J., Peng, Q., Zheng, C., Lyu, L., Yuan, J., Kang, M., 2013. Temporal-spatial distribution of nitrogen in the Dongjiang River and its tributaries. Resour. Sci. 35 (3), 505-513.

Lindenschmidt, K.E., Fleischbein, K., Baborowski, M., 2007. Structural uncertainty in a river water quality modelling system. Ecol. Model. 204 (3-4), 289-300.

Liu, R., Sun, C., Han, Z., Chen, L., Huang, Q., Chen, Y., et al., 2012. Water environmental capacity calculation based on uncertainty analysis: a case study in the Baixi watershed area, china. Proc. Environ Sci. 13, 1728-1738.

Mannina, G., Viviani, G., 2010. An urban drainage storm water quality model: model development and uncertainty quantification. J. Hydrol. 381 (3-4), 248-265.

Nolan, B.T., Hitt, K.J., Ruddy, B.C., Barbara, C., 2002. Probability of nitrate contamination of recently recharged groundwater in the Conterminous United States. Environ. Sci. Technol. 36 (10), 2138-2145.

Owen, A.B., 1992. A central limit theorem for Latin Hyper-cube sampling. J. R. Stat. Soc. B 54 (2), 541-551.

Radwan, M., Willems, P., Berlamont, J., 2004. Sensitivity and uncertainty analysis for river quality modelling. J. Hydroinformatics 6 (2), 83-99.

Rezaie, K., Amalnik, M.S., Gereie, A., Ostadi, B., ShakhseNiaee, M., 2007. Using extended Monte Carlo simulation method for the improvement of risk management: consideration of relationships between uncertainties. Appl. Math. Comput. 190 (2), 1492-1501.

Rezaie, K., Gereie, A., Ostadi, B., Shakhseniaee, M., 2009. Safety interval analysis: a risk-based approach to specify low-risk quantities of uncertainties for contractor's bid proposals. Comput. Ind. Eng. 56 (1), 152-156.
Ryzhakov, A.V., Kukkonen, N.A., Lozovik, P.A., 2010. Determination of the rate of ammonification and nitrification in natural water by kinetic method. Water Resour. 37 (1), 70-74.

Saleh, F., Ducharnea, A., Flipob, N., Oudina, L., Ledoux, E., 2013. Impact of river bed morphology on discharge and water levels simulated by a 1D Saint-Venant hydraulic model at regional scale. J. Hydrol. 476, 169-177.

Shen, Z., Hong, Q., Yu, H., Niu, J., 2010. Parameter uncertainty analysis of non-point source pollution from different land use types. Sci. Total Environ. 408 (8), 1971-1978.

Stein, M., 1987. Large sample properties of simulations using Latin Hypercube sampling. Technometrics 29 (2), 143-151.

Stępień, I., 1984. On the numerical solution of the Saint-Vénant equations. J. Hydrol. 67 (1-4), 1-11.

Tan, K., Chen, Q., Mao, J., Li, W., 2007. The self-perification capacity of the outlet of Daqinghe River: experiment part. Acta Ecol. Sin. 27 (11), 4736-4742.

Tutmez, B., 2009. Assessing uncertainty of nitrate variability in groundwater. Ecol. Inform. 4 (1), 42-47.

Van Griensven, A., Meixner, T., Grunwald, S., Bishop, T., Diluzio, M., Srinivasan, R., 2006. A global sensitivity analysis tool for the parameters of multi-variable catchment models. J. Hydrol. $324(1-4), 10-23$.

Wang, H.D., 2002. Assessment and prediction of overall environmental quality of Zhuzhou City, Hunan Province, China. J. Environ. Manag. 66 (3), 329-340.

Wang, H.D., Wang, S.H., Bao, Q.S., Qi, Z., 1995. On regional differentiation of river water environment capacity and strategies to control water environment pollution in China. Chin. Geogr. Sci. 5 (2), 116-124.

Warmink, J.J., Janssen, J.A.E.B., Booij, M.J., Krol, M.S., 2010. Identification and classification of uncertainties in the application of environmental models. Environ. Model. Software 25 (12), 1518-1527. 